\title{
Outcomes of extracorporeal life support for low cardiac output syndrome after major cardiac surgery
}

\author{
Sung Jun Park, MD, Joon Bum Kim, MD, Sung-Ho Jung, MD, PhD, Suk Jung Choo, MD, PhD, \\ Cheol Hyun Chung, MD, PhD, and Jae Won Lee, MD, PhD
}

\begin{abstract}
Objective: Extracorporeal life support (ECLS) is a widely accepted modality for the treatment of postoperative low cardiac output syndrome (LCOS) after major cardiac surgery by providing temporary circulatory support for the stunned myocardium. We sought to identify the factors that affect outcomes of ECLS for postoperative LCOS.
\end{abstract}

Methods: From 2005 to 2011, of a total of 9267 adult patients underwent major cardiac surgery, 93 patients (aged, $60.6 \pm 13.8$ years; 47 women) underwent ECLS to treat postoperative LCOS.

\begin{abstract}
Results: Thirty-nine (41.9\%) patients were weaned off ECLS successfully, and 1 patient underwent heart transplantation. A final total of 23 patients $(24.3 \%)$, including 1 heart transplantation recipient, survived until the end of the follow-up period (median, 611 days; range, 125-2247 days). On logistic regression analysis, old age $(P=.001)$, a high blood lactate level before ECLS initiation $(P<.001)$, cardiopulmonary bypass weaning failure after surgery $(P<.001)$, and postoperative bleeding $(P=.012)$ were independent factors associated with mortality. In contrast, administration of anticoagulant nafamostat mesilate $(P=.040)$ was found to be associated with improved outcomes of ECLS. When the predictive value of pre-ECLS blood lactate level for mortality was assessed using the receiver operating characteristic curve, the greatest accuracy was obtained at the cutoff value of $7.9 \mathrm{mmol} / \mathrm{L}$, with $63 \%$ sensitivity and $68 \%$ specificity.
\end{abstract}

Conclusions: High lactate level before ECLS is an independent predictor of mortality after ECLS, necessitating earlier ECLS implementations before profound lactic acidosis develops. Moreover, nafamostat mesilate should be considered as alternative to heparin to reduce the risk of bleeding in these high-risk patients. ( $\mathrm{J}$ Thorac Cardiovasc Surg 2014;147:283-9)

Extracorporeal life support (ECLS) is a widely accepted modality for the treatment of postoperative low cardiac output syndrome (LCOS) after major cardiac surgery. ${ }^{1-5}$ By providing temporary circulatory support for the stunned myocardium, ECLS allows time for cardiac recovery. ${ }^{6}$ When the failing heart is unlikely to recover despite prolonged ECLS for more than 48 to 72 hours, either implantation of a ventricular assist device (VAD) or heart transplantation (HT) is desirable before the onset of endorgan insults. ${ }^{2,7}$ Unfortunately, these destination therapies for irreversible cardiac insults are still practically unavailable in many developing countries because of their cost and the limited availability of donor hearts. In South Korea, for instance, the National Health Insurance Corporation has not approved the implantation of VADs

\footnotetext{
From the Department of Thoracic and Cardiovascular Surgery, Asan Medical Center, University of Ulsan College of Medicine, Seoul, Korea.

Disclosures: Authors have nothing to disclose with regard to commercial support.

Received for publication Sept 7, 2012; revisions received Oct 9, 2012; accepted for publication Nov 6, 2012; available ahead of print Dec 7, 2012.

Address for reprints: Joon Bum Kim, MD, Department of Thoracic and Cardiovascular Surgery, Asan Medical Center, University of Ulsan College of Medicine, 388-1 Pungnap-dong Songpa-gu, Seoul 138-736, South Korea (E-mail: jbkim1975@ amc.seoul.kr).

0022-5223/\$36.00

Crown Copyright $\subset 2014$ Published by Elsevier Inc. on behalf of The American Association for Thoracic Surgery

http://dx.doi.org/10.1016/j.jtcvs.2012.11.006
}

because of the associated costs. Furthermore, given that the number of donor hearts is very limited in Korea, bridging to HT is rarely successful in cases of postoperative irreversible heart failure. ${ }^{8}$ Consequently, the recovery of cardiac function by the use of ECLS may be the only option for management of postoperative LCOS after cardiac surgery in many countries under similar conditions. In these regards, there have been only a few reports related to the use of ECLS as a "bridge-to-recovery" for LCOS after cardiac surgery. Therefore, the present study aimed to evaluate the early outcomes of ECLS after major cardiac surgery and to determine the predictive factors of mortality.

\section{PATIENTS AND METHODS \\ Patients}

Between May 2005 and December 2011, 9267 adult patients underwent major cardiac surgery at the Asan Medical Center, Seoul, Korea. These operations included valve surgery, coronary artery bypass grafting, aortic surgery, resectioning of cardiac tumors, pericardiectomy, pulmonary thromboembolectomy, and HT. Among these patients, $103(1.1 \%)$ required postoperative ECLS for LCOS. The exclusion of 10 patients who received ECLS preoperatively left a final cohort that comprised 93 patients and formed the subject population in this study. The breakdown of patients with different clinical situations that required ECLS were as follows: (1) 39 patients with usual postoperative LCOS that was unresponsive to inotropic drugs or intra-aortic balloon pumping (IABP), (2) 21 patients with witnessed cardiac arrest that was unresponsive to standard advanced 


$$
\begin{aligned}
& \text { Abbreviations and Acronyms } \\
& \text { ACT }=\text { activated clotting time } \\
& \text { CI }=\text { confidence interval } \\
& \text { CPB }=\text { cardiopulmonary bypass } \\
& \text { ELCS }=\text { extracorporeal life support } \\
& \text { HR }=\text { hazard ratio } \\
& \text { HT }=\text { heart transplantation } \\
& \text { IABP }=\text { intra-aortic balloon pumping } \\
& \text { LCOS }=\text { low cardiac output syndrome } \\
& \text { VAD }=\text { ventricular assist device }
\end{aligned}
$$

cardiopulmonary life support, and (3) 33 patients with postoperative cardiopulmonary bypass (CPB) weaning failure. The study was approved by the institutional ethics committee/review board of the University of Ulsan, and the requirement for informed patient consent was waived in view of the retrospective nature of the study.

\section{ECLS Devices}

In all 93 patients, venoarterial ECLS was administered via peripheral cannulation involving the common femoral artery and vein or internal jugular vein. The ECLS system consisted of a centrifugal pump, a hollow-fiber membrane oxygenator with an integral heat exchanger, and a heparin-bound circuit. Three types of ECLS system were used: the Capiox emergency bypass system (Terumo, Tokyo, Japan) was used for 80 ( $86 \%$ ) patients, the PLS system (Maquet, Hirrlingen, Germany) for $6(6.5 \%)$, and the Bio-Console 560 system (Medtronic, Minneapolis, MN) for 7 (7.5\%) patients.

\section{Anticoagulation}

Before cannulation, an intravenous heparin bolus of $100 \mathrm{U} / \mathrm{kg}$ was administered to achieve a celite activated clotting time (ACT) (measured using a Hemochron 401 machine; Soma Technology, Bloomfield, Conn) of 300 seconds, except in patients with a high risk of bleeding or in patients who were actively bleeding. The latter 2 classes of patients received a half dose of heparin. After the patients were connected to the ECLS circuit, the ACT was normally maintained within a range of 180 to $200 \mathrm{sec}-$ onds. However, when hemorrhage had occurred or was anticipated, an attempt was made to ensure a lower ACT of 160 to 180 seconds. During the weaning process, an ACT of less than 200 seconds was achieved by significantly reducing the pump flow rate. Whenever CPB weaning failed after surgery, ECLS was performed. Heparin was then replaced by protamine sulfate, which was administered at a dose $25 \%$ lower than normally used.

In 2010, we began to use nafamostat mesilate (Futhan; Torii Pharmaceutical, Tokyo, Japan), a synthetic serine protease inhibitor, as an alternative anticoagulant to heparin for actively bleeding patients immediately after surgery. For these patients, a half dose of heparin was administered before cannulation, and ACT was maintained within 160 to 180 seconds after the administration of a starting dose of $0.75 \mathrm{mg} / \mathrm{kg}$ nafamostat mesilate. The maintenance dose of nafamostat mesilate was adjusted between $0.5 \mathrm{mg} /$ $\mathrm{kg}$ and $1 \mathrm{mg} / \mathrm{kg}$ according to hourly measurements of ACT.

\section{ECLS Management}

The ECLS blood flow was maintained at a cardiac index of at least 2.4 $\mathrm{L} \cdot \mathrm{min}^{-1} \cdot \mathrm{m}^{-2}$. The mean arterial blood pressure was targeted at 60 to 70 $\mathrm{mm} \mathrm{Hg}$. To maintain the appropriate mean arterial pressure, we administered vasopressors as needed, rather than inotropic agents. The patients' hematocrit values were maintained at $30 \%$ to $35 \%$, and platelets were transfused when the platelet count was less than $100 \times 10^{3} / \mathrm{mm}^{3}$ for high bleeding risk patients and $50 \times 10^{3} / \mathrm{mm}^{3}$ otherwise. An antegrade perfusion catheter was routinely placed distal to the arterial cannulation site for distal limb perfusion, except in instances in which this placement failed owing to technical difficulties. If signs of ischemia in the distal limbs developed, we changed the arterial cannulation to the opposite side of the femoral artery.

Successful weaning was defined as the separation from ECLS without mortality over a 24-hour period without resumption of ECLS. ${ }^{9}$ Generally, the weaning process started with the prospect of the recovery of cardiac function when echocardiography showed adequate ventricular filling and an ejection fraction of greater than $30 \%$ to $35 \%$ at ECLS flow of a cardiac index of $1.0 \mathrm{~L} \cdot \mathrm{min}^{-1} \cdot \mathrm{m}^{-2}$. As ECLS weaning proceeded, the ECLS flow was gradually reduced to $0.5 \mathrm{~L} / \mathrm{min}$. If the hemodynamic parameters remain stable for 30 minutes at the ECLS flow of $0.5 \mathrm{~L} / \mathrm{min}$, ECLS was removed from the bedside.

\section{Statistical Analysis}

Categorical variables are presented as frequencies and percentages and were compared using the $\chi^{2}$ test or Fisher's exact test. Continuous variables are expressed as mean \pm standard deviation and were compared using the Student unpaired $t$ test. For multivariable analyses of mortality data, a logistic regression model was used. Variables with a $P$ value $\leq .20$ in univariable analyses were candidates for the multivariable models. Multivariable analyses involved a backward elimination technique, and only variables with a $P$ value $\leq .10$ were used in the final model. Results were expressed as a hazard ratio (HR) with $95 \%$ confidence intervals (CIs). The predictive value of pre-ECLS lactate level for mortality was evaluated by analyzing areas under receiver operating characteristic curves, with their $95 \%$ CIs. The optimal cutoff value corresponded to the value with the greatest accuracy. All reported $P$ values are 2-sided. Statistical analyses were performed with SPSS 18.0 for Windows Software (SPSS Inc, Chicago, Ill).

\section{RESULTS}

The baseline characteristics of the patients are listed in Table 1 . The patients who died were older and required a longer CPB time during surgery than those who survived. The preoperative echocardiographic data, however, showed no significant differences between the 2 groups.

Table 2 compares the variables related to ECLS management and complications in patients according to their final vital status. The levels of serum lactate level before ECLS were significantly higher in patients who died than in those in the group of survivors. Twenty-one $(22.6 \%)$ patients were supported with an IABP before ECLS was begun. For $33(35.4 \%)$ patients, ECLS commenced in the operating room, immediately after the main cardiac procedure, and as a result of CPB weaning failure. For the remaining 60 patients, ECLS commenced in the intensive care unit owing to delayed circulatory collapse after cardiac surgery. Among these 60 patients, 21 patients had cardiac arrest while ECLS was being instituted, and the median arrest time before the initiation of ECLS was 31 minutes (range, 3-142 minutes). Including these 21 patients, the median time interval from the end of the operation to the initiation of ECLS in the intensive care unit was 13.5 hours (range, 0.6-702.1 hours).

\section{Overall Outcomes}

Details of complications that arose during ECLS are provided in Table 2. Twenty-five (26.9\%) patients required 
TABLE 1. Baseline characteristics of the patients who underwent ECLS after major cardiac surgery

\begin{tabular}{|c|c|c|c|c|}
\hline Variables & $\begin{array}{c}\text { Total } \\
(\mathbf{n}=93)\end{array}$ & $\begin{array}{r}\text { Survived } \\
(\mathbf{n}=\mathbf{2 3})\end{array}$ & $\begin{array}{c}\text { Died } \\
(\mathbf{n}=\mathbf{7 0})\end{array}$ & $\boldsymbol{P}$ \\
\hline Age, y & $60.6 \pm 13.8$ & $54.2 \pm 16.7$ & $62.7 \pm 12.2$ & .033 \\
\hline Male gender $(\%)$ & $46(49.5)$ & $13(56.5)$ & $33(47.1)$ & .48 \\
\hline Body surface area, $\mathrm{m}^{2}$ & $1.65 \pm 0.2$ & $1.64 \pm 0.18$ & $1.66 \pm 0.20$ & .64 \\
\hline Hypertension (\%) & $41(44.1)$ & $9(39.1)$ & $32(45.7)$ & .64 \\
\hline Diabetes mellitus (\%) & $17(18.3)$ & $5(21.7)$ & $12(17.1)$ & .76 \\
\hline \multicolumn{5}{|l|}{$\begin{array}{l}\text { Echocardiographic } \\
\text { data }\end{array}$} \\
\hline $\begin{array}{l}\text { LV end-systolic } \\
\text { dimension, mm }\end{array}$ & $38.0 \pm 12.7$ & $42.8 \pm 15.5$ & $36.3 \pm 11.3$ & .083 \\
\hline $\begin{array}{l}\text { LV end-diastolic } \\
\text { dimension, } \mathrm{mm}\end{array}$ & $54.4 \pm 10.4$ & $57.7 \pm 11.8$ & $53.2 \pm 9.8$ & .12 \\
\hline LV ejection fraction & $52.4 \pm 15.6$ & $47.5 \pm 18.3$ & $54.1 \pm 14.3$ & .13 \\
\hline LV mass, $\mathrm{g}$ & $200.9 \pm 80.9$ & $202.1 \pm 69.5$ & $200.5 \pm 85.0$ & .93 \\
\hline Operation type & & & & .11 \\
\hline Valve surgery $(\%)$ & $28(30.1)$ & $8(34.8)$ & $20(28.6)$ & \\
\hline CABG $(\%)$ & $21(22.6)$ & $6(26.1)$ & $15(21.4)$ & \\
\hline Valve + CABG $(\%)$ & $12(16.1)$ & $1(4.3)$ & $11(15.7)$ & \\
\hline Aorta surgery (\%) & $5(5.4)$ & $0(0)$ & $5(7.1)$ & \\
\hline $\begin{array}{c}\text { Aorta }+ \text { valve or } \\
\text { CABG }(\%)\end{array}$ & $14(15.1)$ & $2(8.7)$ & $12(17.1)$ & \\
\hline Others $(\%)$ & $13(14.0)$ & $6(26.1)$ & $7(10)$ & \\
\hline $\begin{array}{l}\text { Previous cardiac } \\
\text { surgery }(\%)\end{array}$ & $9(9.7)$ & $1(4.3)$ & $8(11.4)$ & .44 \\
\hline ACC time, $\min$ & $132.2 \pm 76.8$ & $130.9 \pm 52.2$ & $132.5 \pm 83.3$ & .93 \\
\hline $\mathrm{CPB}$ time, $\min$ & $215.0 \pm 152.6$ & $177.6 \pm 78.3$ & $262.9 \pm 149.0$ & .014 \\
\hline
\end{tabular}

Values are $\mathrm{n}(\%)$ or mean \pm standard deviation. $E C L S$, Extracorporeal life support; $L V$, left ventricle; $C A B G$, coronary arterial bypass grafting; $A C C$, aorta crossclamp; $C P B$, cardiopulmonary bypass.

reoperation owing to mediastinal bleeding, and $11(11.8 \%)$ died of uncontrolled bleeding immediately after the operation, while on ECLS. Among 14 (15.1\%) patients who had complications associated with distal limb ischemia, 2 underwent toe amputation. New-onset neurologic events occurred in 7 (7.5\%) patients, including intracerebral hemorrhage in 3 , subdural hemorrhage in 1 , cerebral infarction in 2, and spinal infarct resulting in quadriplegia in 1 further patient. Six $(6.5 \%)$ patients had complications that involved bowel infarction and all died of multiple organ failure, including 2 patients who underwent bowel resection.

Figure 1 summarizes the outcomes of ECLS. One patient underwent a successful HT and survived. The successful weaning rate was $41.9 \%$ (39/93). Fifteen patients died after successful weaning from ECLS in hospital. Of these 15 patients, 5 had multiple organ failure, 2 had profound cardiac failure, 2 had sepsis, 2 had panperitonitis, 2 had aortic rupture, 1 had intracerebral hemorrhage, and 1 had gastrointestinal bleeding. Hence, 24 patients survived until the time they were discharged. During follow-up, 1 patient died of sepsis owing to graft infection after an ascending aorta replacement 182 days after the operation. Another patient died of heart failure 742 days after coronary artery bypass
TABLE 2. ECLS data for patients who did and did not survive

\begin{tabular}{|c|c|c|c|c|}
\hline Variables & $\begin{array}{c}\text { Total } \\
(\mathbf{n}=93)\end{array}$ & $\begin{array}{c}\text { Survived } \\
(\mathrm{n}=\mathbf{2 3})\end{array}$ & $\begin{array}{c}\text { Died } \\
(n=70)\end{array}$ & $\boldsymbol{P}$ \\
\hline \multicolumn{5}{|l|}{$\begin{array}{l}\text { Clinical situation of } \\
\text { ECLS implantation }\end{array}$} \\
\hline $\begin{array}{l}\text { At the end of } \\
\text { operation }(\%)\end{array}$ & $33(35.4)$ & $5(21.7)$ & $28(40)$ & .14 \\
\hline Arrest (\%) & $21(22.6)$ & 4 (17.4) & $17(24.3)$ & .58 \\
\hline $\begin{array}{l}\text { Interval from operation } \\
\text { finish to ECLS, } \mathrm{h}\end{array}$ & 13.5 & $15.6(3-51)$ & $10.6(0.6-702)$ & .067 \\
\hline $\begin{array}{l}\text { Blood } \mathrm{pH} \text { level before } \\
\text { initiating ECLS }\end{array}$ & $7.31 \pm 0.11$ & $7.33 \pm 0.11$ & $7.31 \pm 0.11$ & .54 \\
\hline $\begin{array}{c}\text { Blood lactate level } \\
\text { before initiating } \\
\text { ECLS, mmol/L }\end{array}$ & $9.06 \pm 4.59$ & $6.55 \pm 3.81$ & $10.24 \pm 4.49$ & .001 \\
\hline Duration of ECLS, $\mathrm{h}$ & 71 & $66.9(0.8-460)$ & $75.8(0.5-517)$ & .20 \\
\hline $\begin{array}{l}\text { Using nafamostat } \\
\text { anticoagulant }(\%)\end{array}$ & $14(15.1)$ & $6(26.0)$ & $8(11.4)$ & .19 \\
\hline \multicolumn{5}{|l|}{$\begin{array}{l}\text { Complications } \\
\text { during ECLS }\end{array}$} \\
\hline $\begin{array}{l}\text { Mediastinal } \\
\text { bleeding (\%) }\end{array}$ & $36(37.6)$ & $5(21.7)$ & $21(42.9)$ & .085 \\
\hline $\begin{array}{l}\text { Reoperation } \\
\text { for bleeding }\end{array}$ & 25 & 5 & 20 & \\
\hline $\begin{array}{l}\text { Massive bleeding } \\
\text { (not operated) }\end{array}$ & 10 & 0 & 11 & \\
\hline Dialysis (\%) & $57(61.3)$ & $12(52.2)$ & $45(64.3)$ & .33 \\
\hline $\begin{array}{l}\text { Neurologic } \\
\text { events }(\%)\end{array}$ & $7(7.5)$ & $1(4.3)$ & $6(8.6)$ & .17 \\
\hline $\begin{array}{l}\text { Lower limb } \\
\quad \text { ischemia }(\%)\end{array}$ & $14(15.0)$ & $3(13.0)$ & $11(15.7)$ & .76 \\
\hline Bowel ischemia (\%) & $6(6.5)$ & $0(0)$ & $6(8.6)$ & .19 \\
\hline $\begin{array}{l}\text { Cannulation-related } \\
\text { complications }(\%)\end{array}$ & $10(10.8)$ & $3(13.0)$ & $7(10)$ & .70 \\
\hline
\end{tabular}

Values are $\mathrm{n}(\%)$ mean \pm standard deviation or median (range). ECLS, Extracorporeal life support.

grafting. A final total of $23(24.3 \%)$ patients, including 1 HT recipient, survived until the end of the follow-up period (median follow-up duration, 611 days; range, 125-2,247 days).

The outcomes of ECLS were summarized according to 3 clinical situations in Figure 2. Notably, the results of the $\mathrm{CPB}$ weaning failure group were poor, showing a weaning rate of $21.2 \%$ and a survival of $15.1 \%$. In contrast, successful weaning and survivals were $53.3 \%$ and $40.0 \%$, respectively, in patients with other clinical setting requiring ECLS.

Both the successful weaning and survivals tended to improve over the course of 7 years of experience (Figure 3).

\section{Independent Predictors of Mortality}

Multivariable analyses revealed that old age (HR, 1.04; 95\% CI, 1.01-1.06; $P=.001$ ), a high serum lactate level before ECLS initiation (HR, 1.13; 95\% CI, 1.06-1.20; $P<.001)$, CPB weaning failure after surgery (HR, 3.22; 


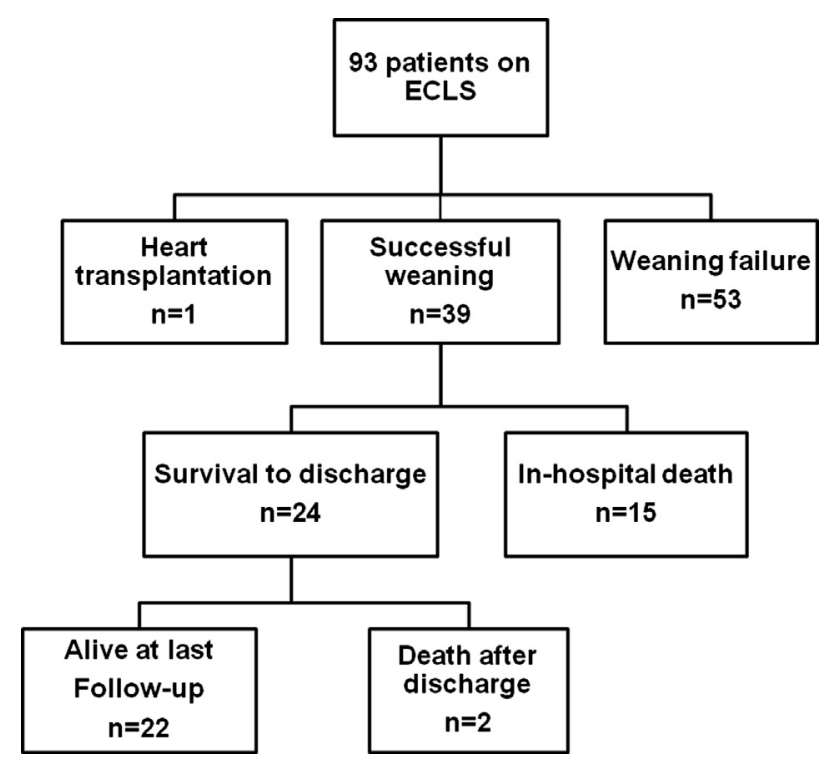

FIGURE 1. Flow chart of the outcomes in patients having extracorporeal life support (ECLS).

95\% CI, 1.79-5.78; $P<.001)$, and postoperative bleeding (HR, 2.00; 95\% CI, 1.17-3.42; $P=.012$ ) were independent factors associated with mortality. In contrast, the administration of the anticoagulant nafamostat mesilate (HR, 0.47; 95\% CI, 0.23-0.97; $P=.040$ ) was found to be associated with an improved outcome of ECLS. The independent predictors for weaning failure from ECLS were also summarized in Table 3.

The predictive value of the serum lactate level before initiation of ECLS for mortality was assessed using the receiver operating characteristic curve. The best accuracy for prediction of mortality was at the cutoff value of 7.9 $\mathrm{mmol} / \mathrm{L}$, with a sensitivity of $63 \%$ and a specificity of $68 \%$, showing an area under the curve of $0.73(95 \% \mathrm{CI}$, $0.61-0.84 ; P=.002$ ) (Figure 4). The patients whose serum lactate level was below the cutoff value of $7.9 \mathrm{mmol} / \mathrm{L}$ before the initiation of ECLS showed higher survivals than the patients whose serum lactate level was greater than 7.9 $\mathrm{mmol} / \mathrm{L}$ (Figure 5).

\section{DISCUSSION}

Notwithstanding improvements in surgical techniques, cardiac anesthesia, and myocardial protection during major cardiac surgery over the past few decades, the incidence of LCOS that requires mechanical support has not decreased. ${ }^{10}$ This can be attributed to the extended indications of surgical candidates, many of whom are older and have impaired ventricular function and comorbidities.

ECLS is a widely accepted temporary mechanical support and is used as "rescue therapy" for emergency and unexpected cardiogenic shock owing to the ease and rapidity with which it can be applied and its ability to rapidly restore the circulation that supports biventricular and respiratory function. Nonetheless, ECLS is strongly associated with complications such as bleeding, limb ischemia, infection, and thromboembolic events, ${ }^{11}$ and the occurrence of these events appears to increase throughout the course of ECLS. Hence, when the failing heart is unlikely to recover after more than 48 to 72 hours of ECLS, it is advisable to bridge this procedure to either implantation of a VAD or HT before end-organ insults or complications arise., ${ }^{2,7}$

Owing to the costs associated with implantable VADs, HT is currently the only solution to treat profound heart

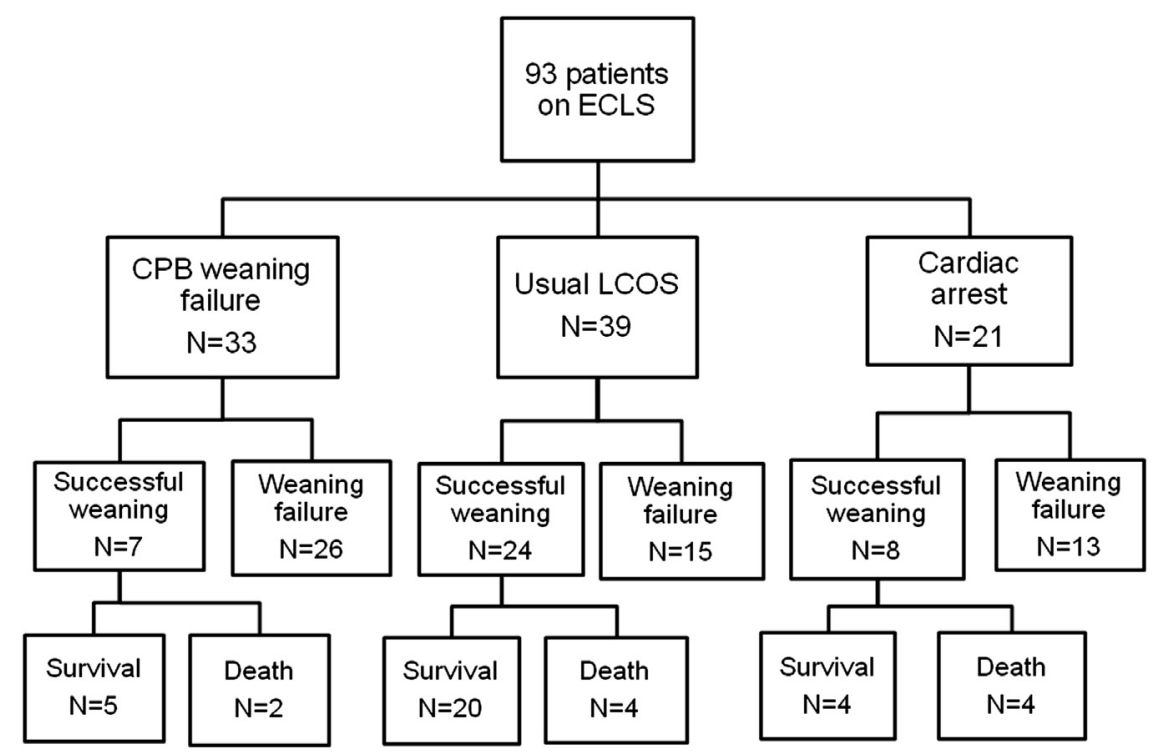

FIGURE 2. Outcomes of extracorporeal life support ( $E C L S$ ) according to 3 different clinical situations. $C P B$, Cardiopulmonary bypass; $L C O S$, low cardiac output syndrome. 


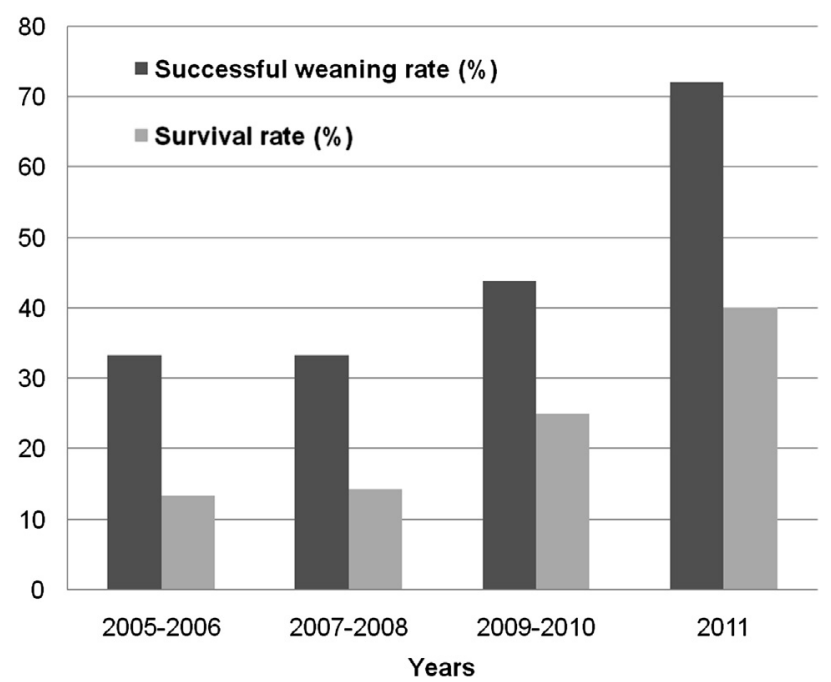

FIGURE 3. Both the successful weaning rate and survival appear to have increases over the course of 7 years of experience $(P<.001)$.

failure in South Korea. Unfortunately, the number of patients waiting for heart transplants is many times greater than the supply of donor hearts, and fewer than 100 heart transplants are performed annually despite the recent increase in rates of organ donation. ${ }^{8}$ Hence, the primary intention of ECLS should be limited to improving cardiac recovery in patients with LCOS after cardiac surgery.

The successful weaning rate from ECLS was measured at $41.9 \%$ in the present study. However, given that $38.4 \%$ of the patients in our study cohort died in the hospital after successful weaning, the hospital survival was only $25.8 \%$. This outcome is comparable with the results of previous studies of ECLS that reported early survival rates ranging from $16 \%$ to $41 \% .^{2-5,12}$ These reports also suggested that there has not been significant improvement in early survival over the past few decades, despite technical improvements in ECLS devices and better management skills. Similarly, a previous analysis of 517 patients who received ECLS has reported a relatively constant survival over the course of a 12-year period. ${ }^{3}$ In contrast, the survival after ECLS at our center appears to have increased over the

TABLE 3. Multivariable risk factors analyses for weaning failure and mortality

\begin{tabular}{|c|c|c|c|c|c|c|}
\hline \multirow[b]{2}{*}{ Variables } & \multicolumn{3}{|c|}{ Weaning failure } & \multicolumn{3}{|c|}{ Mortality } \\
\hline & HR & $95 \%$ CI & $P$ & HR & $95 \%$ CI & $P$ \\
\hline Age & 1.03 & $1.00-1.07$ & .089 & 1.04 & $1.01-1.06$ & $.001 *$ \\
\hline $\begin{array}{l}\text { High serum lactate } \\
\text { level before ECLS }\end{array}$ & 1.14 & $1.01-1.28$ & $.028 *$ & 1.13 & $1.06-1.20$ & $<.001 *$ \\
\hline $\begin{array}{l}\mathrm{CPB} \text { weaning failure } \\
\text { after surgery }\end{array}$ & 6.50 & $2.03-20.79$ & $.002 *$ & 3.22 & $1.79-5.78$ & $<.001^{*}$ \\
\hline $\begin{array}{l}\text { Using nafamostat } \\
\text { anticoagulant }\end{array}$ & 0.33 & $0.09-1.23$ & .099 & 0.47 & $0.23-0.97$ & $.04 *$ \\
\hline
\end{tabular}

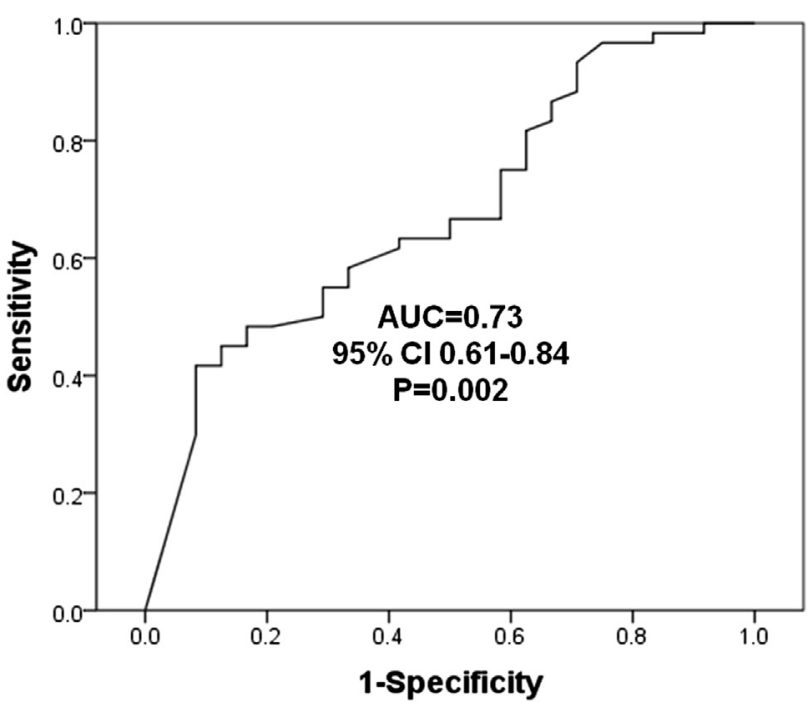

FIGURE 4. Receiver operating characteristic curve for the predictive value of serum lactate level for mortality. AUC, Area under the curve; $C I$, confidence interval.

past 7 years of the study period, with a rate of $40 \%$ for the past 2 years (Figure 2). A reduction in the frequency of bleeding complications, which is associated with the use of nafamostat mesilate for anticoagulation, may account for this better outcome. The low lactate levels in our patients before the initiation of ECLS also likely contributed to the result.

Recent studies have demonstrated that older age, evidence of organ system dysfunction, a history of cardiac surgery, extensive aortic operations, neurologic events, and failure to use an IABP are all predictors of mortality during ECLS. ${ }^{3,4,13}$ Our current findings, however, suggest that advanced age, high levels of serum lactate before ECLS initiation, CPB weaning failure at the end of the operation, postoperative bleeding, and nonuse of

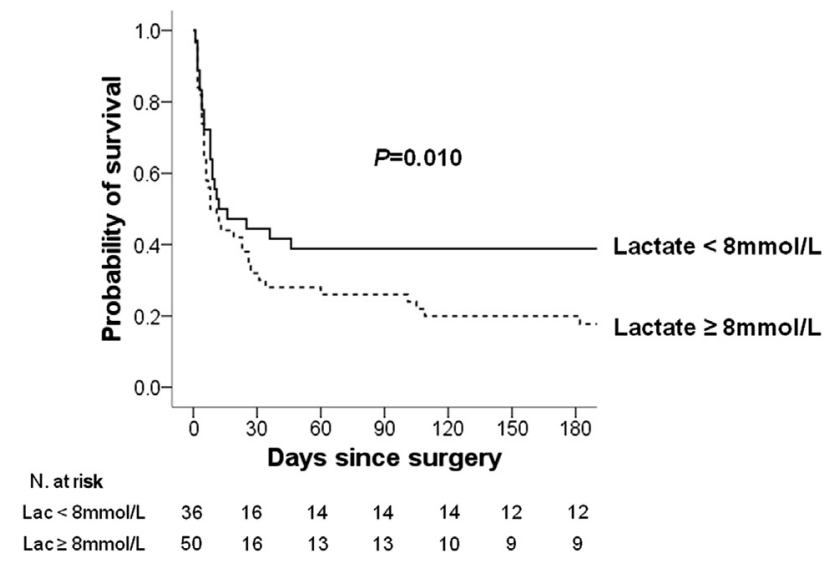

FIGURE 5. Kaplan-Meier analysis revealing differences in mortality according to the serum lactate ( $\mathrm{Lac}$ ) level before the initiation of extracorporeal life support. 
nafamostat mesilate are also predictive of mortality during ECLS.

The discrepancies in the results between this study and the cited studies may be attributed to the differences in the subject patient population and discrepancies in analytic viewpoints. New-onset neurologic events, for instance, occurred in 7 patients during ECLS in the present study, and most of these patients died $(n=6,85.7 \%)$. Although the neurologic events were strongly related to resultant mortality, we believe the causal relationship between the neurologic events and mortality is difficult to be proven in a limited number of patients. This particularly matters because the neurologic damage may be one of the consequences in the process of irreversible multiple organ damage rather than an independent risk factor of mortality. For these reasons, we did not include the neurologic events as one of the candidate risk covariates when determining the risk factors of mortality in this study. The concomitant usage of IABP during ECLS was believed to provide superior coronary perfusion potentially leading to more favorable outcomes. ${ }^{3,4,13}$ In the present study, however, there were no significant differences in overall clinical outcomes between the IABP group and the nonIABP group. Regarding this issue, we may find a clue from a recently published study that prospectively randomized patients to IABP support versus no IABP support in the setting of acute myocardial infarction presenting with shock. ${ }^{14}$ The study found no additional benefit from IABP in these patients. We believe that the sufficient coronary perfusion pressure can be achieved by maintaining mean arterial blood pressure over $60 \mathrm{~mm} \mathrm{Hg}$ even without IABP in the setting of ECMO support. Moreover, IABP may carry further risks of complications related to vascular access. Risk versus benefit of additional IABP in the setting of ECMO support may need further verifications through prospective studies.

The early initiation of ECLS before the onset of profound cardiopulmonary collapse and secondary organ injuries is ideal. Outcomes of ECLS were significantly associated with the severity of pre-ECLS cardiogenic shock, as measured by lactate levels. ${ }^{3,15}$ Our data also suggest that high lactate levels are associated with adverse outcomes. We routinely measured the serum lactate level every 2 to 3 hours, and the value just before the initiation of ECLS was analyzed to determine the timing appropriate for the initiation of ECLS. Previous studies of ECLS after postcardiotomy cardiogenic shock indicated that postoperative mediastinal bleeding was the major problem in the management of this treatment. ${ }^{3,12,16}$ To reduce bleeding complications, we maintained blood cell components and coagulation factors at adequate levels and routinely administered aprotinin or tranxeamic acid. Despite these efforts, the redo thoracotomy rate for the correction of excessive bleeding ranged from $40.0 \%$ to $87.3 \%$.

In 2010, we began to administer nafamostat mesilate (Futhan; Torii Pharmaceutical, Tokyo, Japan) to the ECLS regimen for patients with a tendency to bleed excessively. Nafamostat mesilate is a synthetic protease inhibitor that inhibits coagulation and fibrinolysis owing to its potent inhibitory activity toward thrombin, plasmin, trypsin, kallikrein, certain coagulation factors (XIIa, Xa), and certain complement factors $(\mathrm{C} 1 \mathrm{r}, \mathrm{C} 1 \mathrm{~s}) .{ }^{17,18}$ The use of nafamostat mesilate has been associated with fewer hemorrhagic complications than heparin during extracorporeal circulation during continuous venovenous hemodiafiltration. ${ }^{19} \mathrm{~A}$ favorable outcome from the use of nafamostat mesilate as an anticoagulant during ECLS was also reported previously. ${ }^{20} \mathrm{Ab}-$ normal bleeding after CPB may be the result of excessive fibrinolysis ${ }^{21,22}$ and/or a transient impairment of platelet function. ${ }^{23,24}$ Murase and colleagues ${ }^{25}$ have demonstrated that nafamostat mesilate inhibits fibrinolysis and preserves both platelet counts and platelet function during CPB and the postoperative course, and it contributes to the reduction of blood loss postoperatively. On the other hand, heparin enhances fibrinolytic activity during $\mathrm{CPB}$, leading to the dissolution of clots and recurrence of bleeding. Fourteen patients in our present study cohort who received nafamostat mesilate for anticoagulation instead of heparin showed a lower occurrence of bleeding complication than patients who received heparin. Of these 14 patients, only $4(28 \%)$ had mediastinal bleeding, compared with $32(40.5 \%)$ of the 79 patients who received heparin and had mediastinal bleeding. However, the difference in frequencies of bleeding complications between the 2 groups was not statistically significant. This may be due to the small number of patients in the nafamostat mesilate group and the fact that the heparin group includes patients without a risk of bleeding complications, whereas the nafamostat mesilate group only contains patients at high risk of bleeding complications. The adequacy of ACT determinations to evaluate the need to monitor the extent of anticoagulation mediated by nafamostat mesilate remains to be established.

\section{Limitations}

This study is subject to the limitations inherent in retrospective studies of observational data from a single center. The nonrandomized design might have affected our results owing to unmeasured confounders, procedure bias, or detection bias. The study was conducted in the setting of a high-volume tertiary referral center in a country with unique medicosocial circumstances where availability of VAD or HT is very limited, and therefore the results may not be generalizable to other centers in different situations.

Although the subject patient number was not small compared with previous studies of ECLS, the absolute number 
of patients enrolled was small, particularly the number of patients who received nafamostat mesilate.

\section{CONCLUSIONS}

Owing to the lack of availability of implantable VAD and limited availability of donor hearts, ECLS has been intended to bridge to cardiac recovery. High lactate levels before ECLS and susceptibility to bleeding complications are independent predictors of mortality after ECLS. Hence, ECLS should be initiated before development of profound lactic acidosis. Moreover, nafamostat mesilate should be considered as an alternative to heparin to reduce the risk of bleeding-related complications in patients at high risk of this occurrence.

\section{References}

1. Magovern GJ Jr, Simpson KA. Extracorporeal membrane oxygenation for adult cardiac support: the Allegheny experience. Ann Thorac Surg. 1999;68:655-61.

2. Fiser SM, Tribble CG, Kaza AK, Long SM, Zacour RK, Kern JA, et al. When to discontinue extracorporeal membrane oxygenation for postcardiotomy support. Ann Thorac Surg. 2001;71:210-4.

3. Rastan AJ, Dege A, Mohr M, Doll N, Falk V, Walther T, et al. Early and late outcomes of 517 consecutive adult patients treated with extracorporeal membrane oxygenation for refractory postcardiotomy cardiogenic shock. J Thorac Cardiovasc Surg. 2010;139:302-11.

4. Doll N, Kiaii B, Borger M, Bucerius J, Krämer K, Schmitt DV, et al. Five-year results of 219 consecutive patients treated with extracorporeal membrane oxygenation for refractory postoperative cardiogenic shock. Ann Thorac Surg. 2004; $77: 151-7$

5. Wu MY, Lin PJ, Lee MY, Tsai FC, Chu JJ, Chang YS, et al. Using extracorporeal life support to resuscitate adult postcardiotomy cardiogenic shock: treatment strategies and predictors of short-term and midterm survival. Resuscitation. 2010;81:1111-6.

6. Kloner RA, Przyklenk K, Kay GL. Clinical evidence for stunned myocardium after coronary artery bypass surgery. J Card Surg. 1994;9:397-402.

7. Pagani FD, Aaronson KD, Swaniker F, Bartlett RH. The use of extracorporeal life support in adult patients with primary cardiac failure as a bridge to implantable left ventricular assist device. Ann Thorac Surg. 2001;71:S77-81.

8. Korean Network for Organ Sharing. Available from: http://www.konos.go.kr/ konosis/common/bizlogic.jsp.

9. Sakamoto S, Taniguchi N, Nakajima S, Takahashi A. Extracorporeal life support for cardiogenic shock or cardiac arrest due to acute coronary syndrome. Ann Thorac Surg. 2012;94:1-7.
10. Meurs KV, Lally KP, Peek G, Zwischenberger JB. Adult cardiac failure: management and use of ECLS. In: Sarani B, Kormos RL, eds. Extracorporeal cardiopul monary support in critical care. 3rd ed. Ann Arbor: Extracorporeal Life Support Organization; 2005. 468.

11. Sidebotham D, McGeorge A, McGuinness S, Edwards M, Willcox T, Beca J. Extracorporeal membrane oxygenation for treating severe cardiac and respiratory failure in adults: part 2-technical considerations. J Cardiothorac Vasc Anesth. 2010;24:164-72.

12. Golding LA, Crouch RD, Stewart RW, Novoa R, Lytle BW, McCarthy PM, et al. Postcardiotomy centrifugal mechanical ventricular support. Ann Thorac Surg. 1992;54:1059-64

13. Smedira NG, Moazami N, Golding CM, McCarthy PM, Apperson-Hansen C, Blackstone EH, et al. Clinical experience with 202 adults receiving extracorporeal membrane oxygenation for cardiac failure: survival at five years. $J$ Thorac Cardiovasc Surg. 2001;122:92-102.

14. Thiele H, Zeymer U, Neumann FJ, Ferenc M, Olbrich HG, Hausleiter J, et al. In traaortic balloon support for myocardial infarction with cardiogenic shock N Engl J Med. 2012;367:1287-96.

15. Chen YS, Ko WJ, Chi NH, Wu IH, Huang SC, Chen RJ, et al. Risk factor screening scale to optimize treatment for potential heart transplant candidates under extracorporeal membrane oxygenation. Am J Transplant. 2004;4:1818-25.

16. Muehrcke DD, McCarthy PM, Stewart RW, Seshagiri S, Ogella DA, Foster RC, et al. Complications of extracorporeal life support systems using heparin-bound surfaces: the risk of intracardiac clot formation. J Thorac Cardiovasc Surg. 1995 110:843-51.

17. Hitomi Y, Ikari N, Fujii S. Inhibitory effect of a new synthetic protease inhibitor (FUT-175) on the coagulation system. Haemostasis. 1985;15:164-8.

18. Fujii S, Hitomi Y. New synthetic inhibitors of $\mathrm{C} 1 \mathrm{r}, \mathrm{C} 1$ esterase, thrombin, plasmin, kallikrein and trypsin. Biochim Biophys Acta. 1981;13(661):342-5.

19. Okajima K, Uchiba M, Murakami K. Nafamosta mesilate. Cardiovasc Drugs Rev. 1995;13:51-65.

20. Han SJ, Kim HS, Kim KI, Whang SM, Hong KS, Lee WK, et al. Use of nafamostat mesilate as an anticoagulant during extracorporeal membrane oxygenation. J Korean Med Sci. 2011;26:945-50.

21. Bick RL. Hemostasis defects associated with cardiac surgery prosthetic devices and other extracorporeal circuits. Semin Thromb Hemostasis. 1985; 11:249-80.

22. Tice DA, Reed GE, Clauss RH, Worth MH. Hemorrhage due to fibrinolysis occurring with open heart surgery. J Thorac Cardiovasc Surg. 1963;46: 673-9.

23. Musial J, Niewiarowski S, Hershock D, Morinelli TA, Colman RW, Edmunds LH Jr. Loss of fibrinogen receptors from the platelet surface during simulated extracorporeal circulation. J Lab Clin Med. 1985;105:514-22.

24. Gluszko P, Rucinski B, Musial J, Wenger RK, Schmaier AH, Colmn RW, et al. Fibrinogen receptors in platelet adhesion to surfaces of extracorporeal circuit Am J Physiol. 1987;252:H615-21.

25. Murase M, Usui A, Tomita Y, Maeda M, Koyama T, Abe T. Nafamostat mesilate reduces blood loss during open heart surgery. Circulation. 1993;88(5 Pt 2): II432-6. 